\title{
MAPPING SYSTEM BETWEEN PROPERTY OF BIM SOFTWARE AND MATERIAL OF ENERGY PLUS FOR OPEN BIM-BASED ENERGY PERFORMANCE ASSESSMENT
}

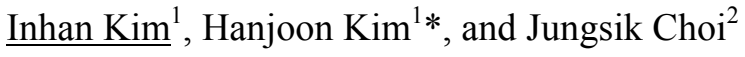 \\ ${ }^{1}$ Department of Architecture, Kyung Hee University, Suwon, Korea \\ ${ }^{2}$ Department of Architecture Engineering, Kyung Hee University, Suwon, Korea \\ * Corresponding author (hanjoonkim0657@gmail.com)
}

\begin{abstract}
Recently, AEC industries have been much research BIM-based energy performance and green building, in Korea. However, Current researches have the lacks of standard guideline for BIM data for BIM-based energy performance assessment and the limitation of interoperability between BIM software. Interoperability is required to Open BIM-based energy performance assessment and it can be exchange, sharing, and compatibility of information between all Open BIMbased software. The purpose of this study is to establish a mapping system between IFC of open BIM standard file format and material of Energy Plus. To achieve this purpose, library and material requirements for the BIM-based energy performance assessment are arranged by investigation and analysis of the researches. A mapping system structure is propose which enables the interoperability between library information of BIM modeling software and material information of energy performance assessment software Energy Plus based on the arranged requirements. Through this research, it is feasible to do the energy performance assessment by the practical use of IFC which was judged as the limitations before, and the application and practical use of mapping system are expected more advanced energy performance assessment software.
\end{abstract}

Keywords: Energy Performance Assessment, Open BIM, Mapping System, IFC, Energy Plus

\section{Introduction}

BIM (Building Information Modeling) can be utilized in the AEC (Architecture, Engineering, and Construction) industries. Especially, BIM in the architectural environment can save the lead time rather than traditional energy performance assessment and also reflect quickly the analysis results of that.

A case of energy performance assessment using $\mathrm{BIM} / \mathrm{IFC}$ based format is insufficient. And traditional energy performance assessment has a few problems. First, traditional analyzing and energy performance assessment are difficult in 2D CAD-based approaches. Second, Autodesk Green Building Studio/Revit or Graphisoft EcoDesigner/ArchiCAD in BIM-based energy performance assessment program is not interoperable. In other words, these programs can only be used in particular BIM software. Third, there is no typical and established analysis method \& guideline for BIM/IFC-based energy performance assessment.

The purpose of this research is to establish a mapping system for energy performance assessment based on BIM/IFC.

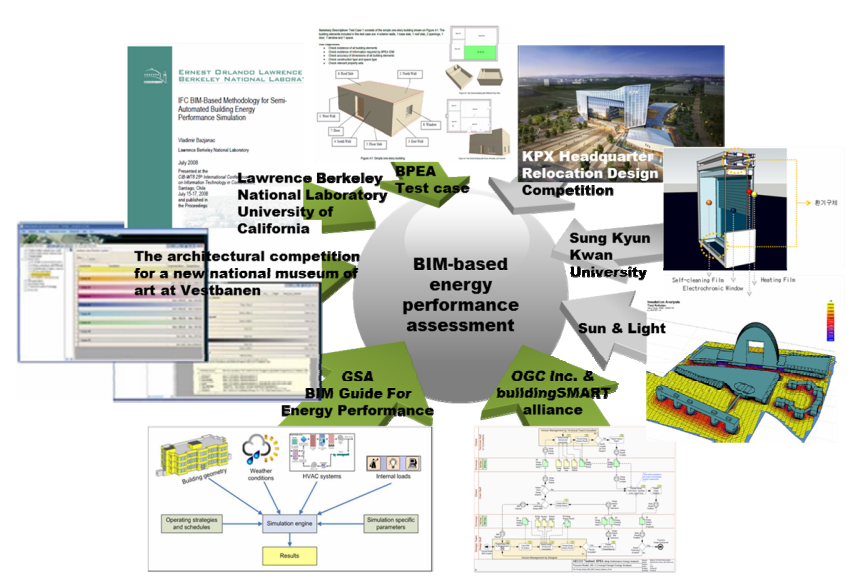

Figure 1 Case works 
2. The necessity for mapping system between BIM modeling software and energy performance assessment software

Through an analysis of energy performance assessment using BIM/IFC cases have been proposed the mapping system between IFC of open BIM standard file format and material of energy performance assessment software. The mapping system IFC of open BIM standard file format and material of energy performance assessment software enables the interoperability between BIM modeling software and energy performance assessment software. The interoperability can be exchange, sharing, and compatibility of information between all Open BIM-based software.

Material of building information can be the embodiment and quantification. Through embodiment and quantification information can be evaluated objective and reliable on energy performance.

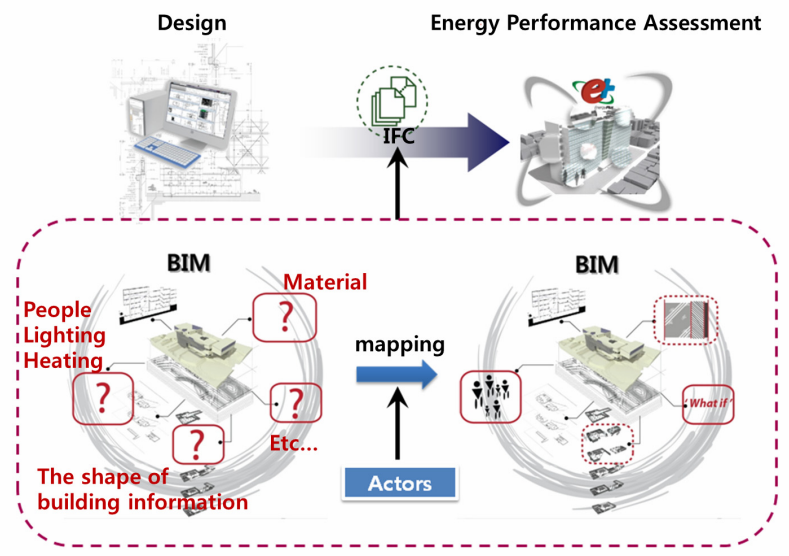

Figure 2 Requirements including the definitions of property and material

\section{Mapping system}

BIM software has a material library. But BIM software material library is not sufficient information for energy performance assessment, and number of material. In order to exact energy performance assessment needs the types of additional information and materials. In this study, the authors have chosen 'ArchiCAD 14' and 'Revit architecture 2011' among the many architectural BIM programs.

The mapping system has been proposed between property of BIM software and material of Energy Plus.

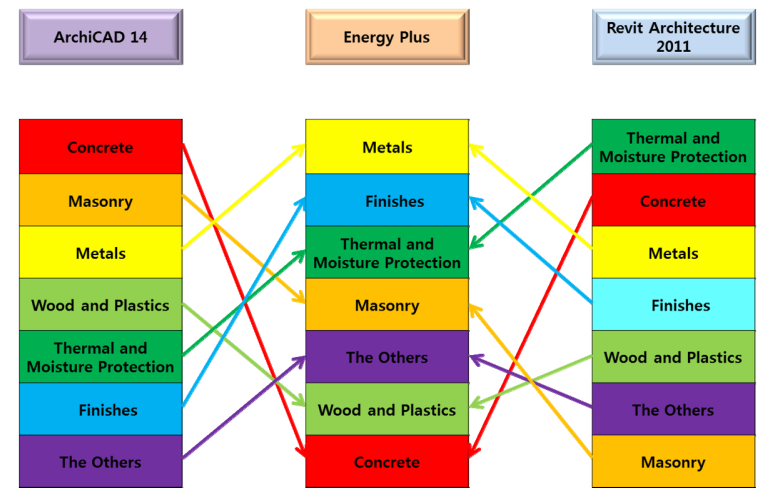

Figure 3 The mapping system between property of BIM software and material of Energy Plus

It is feasible to do the energy performance assessment by the practical use of IFC which was judged as the limitations before, and the application and practical use of mapping system are expected more advanced energy performance assessment software.

\section{ACKNOWLEDGEMENT}

This work was supported by the National Research Foundation of Korea(NRF) grant funded by the Korea government(MEST) (No. 2010-0029196).

\section{REFERENCES}

[1] Ole Kristian Kvarsvik, "National Museum at Vestbanen Architect Competition BIM Requirements - and Results," STATSBYGG, 2009.

[2] GSA, “GSA BIM Guide series 05”, 2009.

[3] Bazjanac, V., "IFC BIM-based Methodology for Semiautomated Building Energy Performance Simulation,” CIB W78 2008 International Conference on Information Technology in Construction, Santiago, Chile, 2008.

[4] Inhan Kim, "Open BIM based Design Guidelines \& Design Quality Evaluation in Korea," Korea Institute of Construction Engineering and Management (KICEM), $3^{\text {rd }}$ seminar of BIM Professionals, 2010.

[5] Inhan Kim, Jieun Kim, Jungsik Choi, "Development of the IFC based IDF Converter for Energy Performance Assessment in the Early Design Phase," Society of CAD/CAM Engineers, Article 16 No.2 pp. 146-155, 2011. 